\title{
TEORI NILAI KESELAMATAN TRANSPORTASI JALAN
}

\author{
Pungkas Hendratmoko \\ Pusat Pengembangan SDM Aparatur Perhubungan, Bogor, Indonesia
}

\begin{abstract}
Abstrak
Penelitian ini menitikberatkan tentang teori nilai keselamatan transportasi jalan/value of road safety (VRS). Tujuannya untuk memberikan opini tentang teori dimaksud. Penelitian dilakukan dengan cara mengulas berbagai pendapat dan data empiris dari teori dimaksud. Hasil penelitian menunjukan bahwa nilai keselamatan transportasi jalan hasilnya beragam bergantung kepada pendekatan perhitungannya. Kesimpulannya diyakini bahwa pendekatan yang dominan dan fleksibel untuk menilai keselamatan transportasi jalan adalah pendekatan perhitungan kemauan untuk membayar/willingness to pay approach (WTP) dengan dengan metode perhitungan berdasarkan preferensi yang dirancang /stated preference (SP).
\end{abstract}

\section{Kata Kunci : kemauan membayar, rancangan preferensi, nilai keselamatan transportasi}

\section{PENDAHULUAN}

Masalah keselamatan lalu lintas sudah menjadi isu dunia yang bukan saja merupakan masalah transportasi, namun juga menjadi masalah sosial kemasyarakatan. Dampak utama kecelakaan fatal lalu lintas adalah kematian. Pada tanggal 11 Mei 2011 disepakati oleh seluruh negara anggota Perserikatan Bangsa Bangsa (PBB) untuk membuat program Decade of Action for Road Safety (DoA) 2011-2020. Target aksi ini untuk mengurangi jumlah korban meninggal dunia pada tahun 2020 sebesar $50 \%$. Berdasarkan data Korlantas Polri, jumlah kecelakaan fatal lalu lintas tahun 2010 di Indonesia mencapai angka 31.234 jiwa, prediksi yang dilakukan sampai dengan tahun 2020 mencapai angka 37.493 jiwa. Untuk mencapai kesuksesan program DoA 2010-2011, jumlah fatalitas harus mampu ditekan menjadi $50 \%$ dari 37.493 jiwa atau 18.747 jiwa pada tahun 2020. Oleh karenanya pada tahun 2020 diharapkan terdapat 88.600 jiwa terselamatkan dari kematian prematur akibat kecelakaan lalu lintas di jalan.

Dampak fatal kecelakaan transportasi jalan sangat terasa pada perekonomian nasional, karena hilangnya kesempatan produksi korban. Badan Kesehatan Dunia/world health organization (WHO) tahun 2004, menjelaskan bahwa kecelakaan transportasi jalan di Indonesia menyebabkan kerugian ekonomi sekitar $2 \%$ dari pendapatan nasional bruto. 
Sejumlah kerugian ekonomi yang disebabkan oleh kecelakaan transportasi jalan tersebut, dikenal sebagai nilai keselamatan transportasi jalan/value of road safety (VRS).

Mengacu pada Oxford Review of Economic Policy (Vol.6, No.2, 1990 : 40), pendekatan yang sering digunakan untuk perhitungan VRS, yaitu : 1) Pendekatan perhitungan produktivitas korban/human capital approach (HC), dan 2) Pendekatan perhitungan kesediaan membayar /willingnes to pay approach (WTP). Seiring dengan hal tersebut hasil penelitiannya juga sangat beragam, sehingga menarik untuk dicermati. Tujuan dari penelitian ini adalah untuk memberikan opini tentang teori dimaksud yang dilakukan dengan cara mengulas berbagai pendapat dan data empiris dari teori dimaksud yang pada akhirnya diharapkan dapat bermanfaat untuk pengembangan ilmu pengetahuan.

\section{KAJIAN TEORI}

Dalam dokumen yang dikeluarkan oleh Overseas Development Administration London (1995 : 1), disebutkan bahwa dampak dari kecelakaan transportasi jalan dapat dikategorikan menjadi empat jenis, yaitu : 1). Kecelakaan fatal atau kecelakaan yang menyebabkan korban meninggal dunia, 2). Kecelakaan serius atau kecelakaan yang menyebabkan korban luka serius sampai dengan cacat permanen, 3). Kecelakaan ringan atau kecelakaan yang menyebabkan korban luka ringan, dan 4). Kerusakan atau kecelakaan yang menyebabkan kerusakan kendaraan.

Dalam kaitannnya dengan hal tersebut, Hill dan Jones-Lee $(1981,1983)$ mengidentifikasi setidaknya terdapat enam pendekatan untuk menilai biaya yang hilang akibat kecelakaan fatal transportasi jalan, yaitu : 1). Pendekatan perhitungan gross output/human capital, 2). Pendekatan perhitungan net output, 3). Pendekatan perhitungan willingnes to pay / value of risk change, 4). Pendekatan perhitungan life insurance, 5). Pendekatan perhitungan court award, dan

6). Pendekatan perhitungan implicit public sector valuation. Menurut Jones-lee (1990 : 39), pendekatan yang biasa digunakan untuk perhitungan VRS adalah pendekatanhuman capital $(\mathrm{HC})$, dan pendekatan willingnes to pay ( WTP).

Pendekatan HC dilakukan dengan metode menghitung produktivitas korban yang terselamatkan dari resiko fatal kecelakaan lalu lintas (meninggal dunia).

Sedangkan pendekatan WTP dilakukan dengan metode menilai preferensi, yaitu dengan cara menanyakan langsung kepada responden tentang preferensinya/ kesediaanya 
membayar/WTP untuk menurunkan jumlah fatalitas kecelakaan lalu lintas. Nilai preferensi/WTP tersebut didefinisikan sebagai jumlah maksimum yang bersedia dibayarkan oleh setiap individu atau kelompok dalam upaya meningkatkan keselamatan atau untuk mengurangi jumlah fatalitas kecelakaan lalu lintas (disebutkan sebagai WTP berkeselamatan).

Perhitungan VRS dengan pendekatan WTP berkeselamatan dilakukan dengan mengacu pada model nilai hidup statistik /value of stastical life (VoSL).

Pada model VoSL menjelaskan tentang nilai rata-rata dari tingkat subtitusi marginal/marginal rate of subtitution (MRS) antara biaya keselamatan dengan penurunan jumlah kecelakaan fatal lalu lintas (Andersson, 2013). Model VoSL diadopsi dari teori ekonomi mikro. Pada model ini yang dimaksud dengan biaya keselamatan adalah kesediaan masyarakat untuk membayar/willingnes to pay (WTP) dalam upaya peningkatan keselamatan transportasi jalan, sedangkan yang dimaksud dengan penurunan jumlah kecelakaan fatal lalu lintas adalah upaya penurunan fatalitas kecelakaan lalu lintas pada kondisi yang dirancang

Model VoSL dapat diilustrasikan sebagai berikut : Apabila di suatu daerah tingkat kecelakaan fatal lalu lintas mencapai 10 korban jiwa per 100.000 penduduk tiap tahunnya berarti secara statistik setiap tahun 10 orang dari 100.000 penduduk akan meninggal dalam kecelakaan fatal lalu lintas. Kemudian apabila pemerintah selaku pengelola jalan menawarkan kepada mayarakat untuk menurunkan tingkat kecelakaan fatal tersebut dari 10 korban jiwa menjadi 5 orang korban jiwa per 100.000 penduduk tiap tahunnya dengan memperbaiki prasarana jalan, dan perlengkapannya, artinya 5 orang akan terselamatkan hidupnya setiap tahun dari setiap 100.000 kehidupan. Untuk menentukan nilai dalam bentuk uang dari penurunan tingkat kecelakaan ini, konsep kesejahteraan ekonomi diterapkan dengan menanyakan kesediaan masyarakat untuk membayar/willingnes to pay (WTP) dalam rangka upaya pemerintah untuk meningkatkan aspek keselamatan. Misalkan saja setiap orang mau membayar USD 50 untuk pengurangan tingkat kecelakaan tersebut, artinya total dana yang bisa dikumpulkan pemerintah dari 100.000 penduduk adalah USD $50 \times 100.000=$ USD 5 juta. Kemudian Nilai Hidup Statistik/Value of Statistical Life (VoSL) dari upaya ini adalah USD 5 juta / 5 nyawa terselamatkan = USD 1 juta per kehidupan. 


\section{PEMBAHASAN}

Sejak diadakannya seminar makalah penelitian tentang penetapan VRS dengan pendekatan WTP pada tahun 1960 an, dan awal tahun 1970 an (Dreze, 1962; Jones Lee, 1974; Mishan, 1971; Scheling 1968) telah terjadi sejumlah besar evaluasi terhadap penetapan VRS baik secara teori maupun empiris. Menurut Jones-lee (Oxford Review of Economic Policy,Vol.6, No.2, 1990 : 41), untuk dapat menstandarisasi penetapan VRS tersebut, lebih tepat dilakukan dengan pendekatan WTP. Pendekatan WTP adalah suatu cara untuk menghitung kemauan masyarakat untuk membayar dalam upaya penurunan jumlah kecelakaan fatal lalu lintas dengan menanyakan langsung kepada masyarakat tentang preferensinya terhadap keselamatan.

Beberapa penelitian tentang penetapan VRS, dan VoSL pada era tahun 1980 an telah dilakukan, dengan pendekatan WTP metode RP, dengan hasil sebagai berikut :

Tabel 3.1. Study VRS-VoSI dengan Pendekatan WTP Metode RP

\begin{tabular}{lcc}
\hline \multicolumn{1}{c}{ Study } & \multicolumn{2}{c}{ VoSL } \\
& \multicolumn{2}{c}{$(£$-sterling, 1989) } \\
\cline { 2 - 3 } & $\begin{array}{l}\text { Nilai rata- } \\
\text { rata MRS }\end{array}$ & $\begin{array}{c}\text { Nilai tengah } \\
\text { MRS }\end{array}$ \\
\hline $\begin{array}{l}\text { Blomquist } \\
(1979)\end{array}$ & 440.000 & - \\
\hline $\begin{array}{l}\text { Jones-Lee } \\
\text { dkk. (1985) }\end{array}$ & 2.000 .000 & 680.000 \\
\hline $\begin{array}{l}\text { Persson } \\
(1989)\end{array}$ & $1.500 .000-$ & $420.000-$ \\
\hline $\begin{array}{l}\text { Maier dkk. } \\
(1989)\end{array}$ & 1.800 .000 & 840.000 \\
\hline
\end{tabular}

Sumber : Oxford Review of Economic Policy,Vol.6, No.2, 1990 : 45

Berbagai macam studi tentang penetapan VRS dengan pendekatan WTP metode RP, hingga saat kini telah banyak dilakukan (seperti yang terakhir : Mouloud dkk., 2014). Studi tersebut biasanya dilakukan dengan pendekatan penggunaan alat pelindung keselamatan, seperti sabuk pengaman, helm sepeda motor, dan lainya (seperti : Blomquist, 1979; Blomquist, Miller dan Levy, 1996; Hakes dan Viscusi, 2007; Jenkins , Owens, dan Wiggins, 2001), atau pendekatan kepemilikan kendaraan pribadi yang berkeselamatan (seperti : Atkinson dan Halvorsen, 1990; Dreyfus dan Viscusi, 1995, Andersson, 2005). 
Selanjutnya studi tentang penetapan VRS dengan pendekatan WTP metode sataed preference (SP) lebih dominan digunakan dibanding metode RP, karena metode SP memiliki kelebihan dibanding metode RP. Salah satu kelebihannya adalah metode SP lebih fleksibel dalam menilai keselamatan transportasi jalan (Andersson dan Lindberg, 2009; Hultkrantz, Lindberg, dan Andersson, 2006; Johannesson, Johansson, dan O'Connor, 1996). Apabila pendekatan WTP dengan metode RP hanya dapat digunakan untuk menilai WTP individu, dan keluarga secara terpisah, berbeda dengan pendekatan WTP dengan metode SP yang mampu menilai WTP keduanya secara bersamaan, selain itu penilaian dengan metode SP bisa mencakup penilaian altutristic responden (Bergstrom, 1982; Andersson dan Linberg, 2009; Jones Lee, 1991).

Berbagai studi tentang penetapan VRS, menurut Andersson dan Treich (2011) lebih didominasi dengan topik penilaian preferensi responden terhadap keselamatan. Pada tahun yang sama Andersson dan Treich (2011), melakukan penelitian tentang VRS, dan diperoleh interval nilai WTP individu yang sangat besar, yaitu : antara USD 150.000 USD 36 milion. Sejak banyak penelitian tentang VRS dengan pendekatan WTP dilakukan, diperoleh banyak variasi nilai WTP individu terhadap peningkatan keselamatan transportasi jalan. Sebagai contoh, nilai WTP individu terhadap peningkatan keselamatan di negara-negara kaya bisa sangat tinggi, dan sangat tidak terkontrol nilainya. Penemuan lainnya, tentang WTP individu terhadap peningkatan keselamatan transportasi jalan yang memiliki interval nilai WTP yang sangat besar (seperti : Hammitt dan Graham, 1999 ; McDaniels 1992). Selanjutnya bukti empiris menjelaskan bahwa nilai WTP dengan metode SP akan lebih besar dibanding nilai WTP dengan metode RP (De Blaeij, Florax, Rietveld dan Verhoef, 2003; Miller, 2000). Yang terkini Tjahjono dan Hendratmoko (2014), menjelaskan bahwa WTP berkeselamatan dengan metode SP, tidak bisa ditanyakan langsung kepada responden di Indonesia, karena akan diperoleh penolakan jawaban. Oleh karenanya, desain pertanyaan WTP berkeselamatan harus dikaitkan dengan variabel lainnya. Pada penelitiannya desain pertanyaan WTP berkeselamatan dikaitkan dengan variabel pemeliharaan kendaraan, dan pemeliharaan kesehatan, dan diperoleh nilai rata-rata WTP berkeselamatan yang berbeda, yaitu : Rp. 4.040.000 untuk pemeliharaan kendaraan, dan Rp.772.000,- untuk pemeliharaan kesehatan. Menurutnya perbedaan tersebut disebabkan karena setiap individu memiliki preferensi yang berbeda antara sejumlah barang. 


\section{KESIMPULAN}

Pendekatan HC lambat laun telah ditinggalkan,karena memiliki keterbatasan yang signifikan (Arthur,1981; Jeremic, dkk.,2012; Jones-Lee dan Loomes, 2003). Keterbatasan tersebut disebabkan karena perhitungannya hanya didasarkan dari produktivitas korban meninggal dunia yang hilang, sedangkan kerugian lainnya yang terdampak dari meninggalnya korban belum terhitung.

Selanjutnya menurut David Pearce dkk., (2002 : 15-16), keselamatan masuk dalam kategori barang non pasar (non marketed goods). Biasanya untuk menetapkan nilai ekonomi barang non pasar digunakan pendekatan WTP. Terdapat dua metode penilaian preferensi pada pendekatan WTP, yaitu : 1) Metode reaveled preference (RP), dan 2) Metode stated preference (SP). Metode RP didasari atas survei preferensi pada kondisi pasar sebenarnya, sedangkan metode SP didasari atas survei preferensi pada kondisi pasar hipotetis (kondisi pasar yang dirancang). Untuk menilai preferensi berkeselamatan dengan metode RP harus dikaitkan dengan barang/jasa yang ada di pasar (marketed goods/sevices). Penelitian tentang perilaku konsumen dalam membeli kendaraan adalah salah satu contohnya, karena setiap kendaraan memiliki kelengkapan keselamatan yang berbeda-beda sesuai harganya (Andersson, 2005; Andersson dan Svensson, 2008; Atkinson dan Halvorsen, 1990; Dreyfus dan Viscusi, 1995). Untuk menilai preferensi berkeselamatan dengan metode SP dilakukan atas dasar model utilitas deterministik dari prespektif teori ekonomi mikro, yang menjelaskan bahwa setiap individu berperilaku sesuai preferensinya.

\section{DAFTAR PUSTAKA}

Andersson, H., 2005. The value of safety as revealed in the Swedish car market: an application of the Hedonic pricing approach. Journal of Risk and Uncertainty, 30(3), $211 \mathrm{e} 239$.

Andersson, H., \& Lindberg, G., 2009. Benevolence and the value of road safety. Accident Analysis \& Prevention, 41(2), 286e293.

Andersson, H., \& Treich, N., 2011. The value of a statistical life. In A. de Palma, R. Lindsey, E. Quinet, \& R. Vickerman (Eds.), A handbook of transport economics (pp. 396e424). Cheltenham, UK: Edward Elgar.

Andersson, H., (2013). Consistency in preference for road safety : an analysis of precautionary and stated behavior, Elsevier.

Andersson, H., 2005. The value of safety as revealed in the Swedish car market: an application of the Hedonic pricing approach. Journal of Risk and Uncertainty, 30(3), $211 \mathrm{e} 239$.

Atkinson, S. E., \& Halvorsen, R., 1990. The valuation of risks to life: evidence from the market for automobiles. Review of Economics and Statistics, 72(1), 133e136 
Bergstrom, T. C., 1982. When is a man's life worth more than his human capital? In M. W. Jones-Lee (Ed.), The value of life and safety (pp. 3e26), North-Holland, Amsterdam, Netherlands.

Blomquist, G. C., Miller, T. R., \& Levy, D. T. (1996). Values of risk reduction implied by motorist use of protection equipment. Journal of Transport Economics and Policy, $30(1), 55 \mathrm{e} 66$.

Blomquist, G., 1979. Value of Life Saving : Implications of Consumption Activity, Journal of Political Economy, 87 : 540-58.

David Pearce, and Ece Ozdemiroglu et al., (2002). Economic valuation with stated preference techniques, departement for transport, local government and region, London.

De Blaeij, A., Florax, R. J. G. M., Rietveld, P., \& Verhoef, E., 2003. The value of statistical life in road safety: a meta-analysis. Accident Analysis and Prevention, 35(6), $973 \mathrm{e} 986$.

Dreyfus, M. K., \& Viscusi, W. K., 1995. Rates of time preference and consumer valuations of automobile safety and fuel efficiency. Journal of Law and Economics, $38(1), 79 \mathrm{e} 105$.

Drèze, J. H., 1962. L’Utilité Sociale d'une Vie Humaine. Revue Française de Reserche Opérationnelle, 6, 93e118.

Hakes, J. K., \& Viscusi, W. K. (2007). Automobile seatbelt usage and the value of statistical life. Southern Economic Journal, 73(3), 659e676.

Hammitt, J. K., \& Graham, J. D. (1999). Willingness to pay for health protection: inadequate sensitivity to probability? Journal of Risk and Uncertainty, 18(1), 33e62.

Hill, P.J., and M.W. Jones Lee, (1981). The costs of traffic accidents and evaluation of accidents prevention in developing countries. In PTRC Summer Annual Meeting.University of Warwick, 13-16 July 1981. London : PTRC Education and Ressearch Services.

Hill, P.J., and M.W. Jones Lee, (1983). The role of safety in higway investment appraisal for developing countries . Acident Analysis and Prevention, 15,355-69.

Hultkrantz, L., Lindberg, G., \& Andersson, C. (2006). The value of improved road safety. Journal of Risk and Uncertainty, 32(2), 151e170.

Jenkins, R. R., Owens, N., \& Wiggins, L. B. (2001). Valuing reduced risks to children: the case of bicycle safety helmets. Contemporary Economic Policy, 19(4), 397e408.

Jones Lee, M. W., 1990. The Value of Transport Safety, Oxford University Press and The Oxford Review of Economic Policy Limited.

Jones Lee, M. W., O'Reilly, D., Philips, P., 1993. The value of preventing non-fatal road injuries: findings of a willingness-to-pay national sample survey. TRL Working Paper WPSRC2, Transport Research Laboratory, Crowthorne.

Jones Lee, M.W. (1990). The value of transport safety. Oxford University Press and The Oxford Review of Economic Policy Limited.

Jones-Lee, M. W., 1974. The value of changes in the probability of death or injury. Journal of Political Economy, 82(4), 835e849.

Jones-Lee, M. W., 1991. Altruism and the value of other people's safety. Journal of Risk and Uncertainty, 4, 213e219.

McDaniels, T. L., 1992. Reference points, loss aversion, and contingent values for auto safety. Journal of Risk and Uncertainty, 5(2), 187e200.

Miller, T. R., 2000. Variations between countries in values of statistical life. Journal.

Mishan, E. J., 1971. Evaluation of life and limb: a theoretical approach. Journal of Political Economy, 79(4).687-705. 
Mouloud, H. et al, 2014. Willingness to pay for road safety improvement, Groupe D'Analyse De Theorie Economique Lyon- ST Etienne of Transport Economics and Policy, 34(2), 169e188.

Schelling, T. C., (1968). The life you save may be your own. In S. B. Chase (Ed.), Problems in public expenditure analysis (pp. 127e162).Washington, D.C., US: The Brookings Institution.

Tjahjono,T., Hendratmoko, P. (2014). Perhitungan kemauan untuk membayar pada penetapan nilai keselamatan transportasi jalan untuk kelompok pengguna jalan tertentu, The $17^{\text {th }}$ FSTPT International Symposium, Jember University. 